UDC 811.111'27

\title{
THE COMMUNICATIVE STATUS OF TOPIC RECONTEXTUALIZATION
}

\author{
Liudmyla Kovalchuk, \\ PhD in Philology, \\ Senior Lecturer of English Philology Department, \\ Lesya Ukrainka Eastern European National University, \\ Lutsk, Ukraine \\ liuda_babula@yahoo.com
}

Received March, 28, 2018; Accepted April, 19, 2018

\begin{abstract}
This article presents a study of the communicative status of topic recontextualization in discourse. A context model is defined as a mental representation of the relevant parameters of a communicative situation in the episodic memory of the interlocutors which provides a thematic coherence of the communication. The study of context is understood in its organic connection with an object of the speaker's thought, or topic, which makes it possible to reveal the cognitive structure of context and to analyze deeply the communicative status of recontextualization).

Recontextualization is defined as a linguo-cognitive operation aimed at functional topic reorientation in the discourse caused by the change of the interlocutors' perspective on the topic. The communicative status of topic recontextualization includes various communicative factors: spatiotemporal inhomogeneity, redistribution of communicative roles, side-participant presence and polytopicality of communication.

Special attention is focused on the study of the lingual means that contribute greatly to topic recontextualization. Lexico-grammatical means function as indicators of retrospective and prospective reference. Communicative tactics of attracting attention, interruption and persuasion signal the redistribution of communicative roles. Speech phonation, the untimely completion of communication, topic change indicates the presence of a side-participant, either as a passive or an active communicative partner, joining in the topic recontextualization in the discourse. A coexistence of two or more topics within the communicative process marks its multiperspectivity.
\end{abstract}

Key words: topic, recontextualization, context model, communicative factors, lingual means.

\section{Introduction}

The study of the functional structure of context and its role in the processes of discourse production and interpretation belongs to the priority trends of modern linguistic cognitively oriented linguistic researches. In present-day linguistics one may observe a fundamental rethinking of the concept of context. Instead of functioning solely as a constraint on linguistic performance, context is treated as a product of language use. A. Duranti and Ch. Goodwin state that "language and context are seen as interactively achieved phenomena, rather than predefined sets of forms and contents" (Duranti \& Goodwin, 1995).

According to T.A. van Dijk, the founder of a new socio-cognitive context theory, context as a mentally construed "subjective representation of relevant 
parameters of a communicative situation in episodic memory of its participants" (Dijk, 2008: 16), exists in terms of context models - the speaker's context model and the listener's context model. Such relevant parameters include time and place, participants, their relationships and goals, knowledge, evaluations and emotions. It presupposes the great importance of the participants' perspective for the analysis of context based on their cognitive-communicative actions. Thus communicative partners generate context models through the prism of the subjective interpretation of a communicative situation in their mental space, which provides a thematic coherence of interaction.

Topic as an object of thought formed in the mind of the speaker and expressed in the discourse can be easily recognized and appropriately identified by the listener under condition of taking into consideration the relevant context model as a mental construct. Thus topic and context stand in a fundamental figure-ground relationship to each other.

Alongside subjectivity, uniqueness and flexibility the most distinctive functional property of context models is their dynamic character. A. Pilkington states, "It should be noted that context construction is a dynamic part of utterance interpretation: context is not static and pre-given as it is in earlier code model accounts" (Pilkington, 1996: 157). It presupposes constant modifications and changes of parameter configuration within context models leading to topic recontextualization in the process of communication. The goal of this paper is to study the communicative status of topic recontextualization, namely the communicative factors and lingual means of topic recontextualization in the discourse.

\section{Methodology and Methods}

The study of the communicative status of topic recontextualization is based on the methodological principles of the activity-based approach and is carried out within the framework of the cognitive-communicative linguistic paradigm. According to the activity-based approach to the discourse study language is no longer understood as a representation of the ready-made knowledge about the world or a passive reflection of the extra-linguistic reality by the subjects of cognition expressed in the set of units of different linguistic levels. Instead it is treated as a kind of an integrated dynamic cognitive activity of the subjects of cognition, i.e. the speaker generates a context model and influences the process of context generation by his interlocutors in their discursive activity.

We used a set of methods of linguistic analysis to fulfil the main goal of the paper. The contextually-interpretation method is applied to establish the system of the continuous context which forms the ground for the topic development in the discourse. The context of generation (the speaker's context model), the context of reception (the listener's context model) and the mini-context of the text fragment are taken into consideration and analyzed. This method is specifically used for the determination of the dynamics of interaction of the interlocutors' context models. The method of discourse analysis is directed towards revealing different social, cultural, mental and other factors that influence the process of discourse production and interpretation. This method allows to identify the main communicative factors of topic recontextualization. The application of the method of conversational analysis is explained by the necessity of revealing the lingual means of topic recontextualization in the discourse. 


\section{Recontextualization as a linguo-cognitive operation}

The perspectival impact of topic contextualization lies in its function to display how interlocutors want their topic to be interpreted, and what choice of informational background characterizes their mental position in relation to the topic.

The present-day understanding of the perspective determines it as "a form of representation by which the parts of an object, or the elements of a complex state of affairs and their interrelations, are construed and presented as if seen from a given point of view (Graumann \& Werner, 2002: 25).

Topical perspective can be defined as a specific way of viewing, understanding and evaluating the points talked about. Perspectivation is mental and communicative activities (perspective-setting and perspective-taking) performed by interlocutors to display their points of view on the given topic. Perspective and perspectivation are studied by Carl F. Graumann, Werner Kallmeyer, Per Linell, Paul Simpson and others (Graumann \& Werner, 2002; Linell, 1998; Simpson, 1993).

As P. Linell states, "since all communication predetermines asymmetries, it is that only by mutual taking the perspective of others we are able to communicate and, thereby, to become aware of our own (and others') perspectivity. The focus on mutual communication with its emphasis on the reciprocity of perspectives gives language a prominent role in the development of world and self knowledge" (Linell, 1998: 14).

Topic recontextualization (Gumperz, 1982), is a linguo-cognitive operation aimed at functional topic reorientation in a discourse caused by the change of the interlocutors' perspective (reperspectivation) on the topic.

Topic recontextualization is regarded as the process of viewing and interpreting the topic by putting it in a new context model. In other words, on the basis of an initial context model (CM1) communicative partners generate potential context models (CM1, CM2, CM3...). The process of recontextualization can be represented as follows: $\mathrm{CM1} \rightarrow \mathrm{CM} 2 \rightarrow \mathrm{CM} 3 \rightarrow \ldots \mathrm{CMn}$.

Consider the following example for modelling the process of topic recontextualization in its general terms. Abbreviations S1 and S2 stand for speaker1 and speaker2.

(1) I (Mr. Henry) walked down the damp gravel driveway looking at the villa through the trees. The windows were all shut but the door was open. I went in and found the major sitting at a table in the bare room with maps and typed sheets of paper on the wall.

S1 "Hello", he said. "How are you?" He looked older and drier.

S2 "I'm good", I said. "How is everything?"

S1 "It's all over", he said. "Take off your kit and sit down”. I put my pack and the two musettes on the floor and my cap on the pack. I brought the other chair over from the wall and sat down by the desk. "It's been a bad summer", the major said. "Are you strong now?"

S2 "Yes. What do you want me to do?"

S1 "The cars are all away. There are six up north at Caporetto. You know Caporetto?"

S2 "Yes", I said. I remembered it as a little white town with a campanile in a valley. It was a clean little town and there was a fine fountain in the square. 
S1 "They are working from there. There are many sick now. The fighting is over. We lost three cars".

S2 "I heard about it".

S1 "Yes, Rinaldi wrote you. Where is Rinaldi?"

$\boldsymbol{S 2}$ "He is here at the hospital. He has had a summer and fall of it".

S1 "It has been bad", the major said. "You couldn't believe how bad it's been. I've often thought you were lucky to be hit when you were".

S2 "I know I was".

$\boldsymbol{S 1}$ "Next year will be worse", the major said. "Perhaps they will attack now. They say they are to attack, but I can't believe it. It is too late..." (Hemingway, 2003: 173-175).

In the example (1) the conversation takes place between the major and the lieutenant who has returned from the military hospital to the front line again. Telling about the present situation (It's all over; The cars are all away; There are six up north at Caporetto; They are working from there; There are many sick now; The fighting is over), the major also informs the lieutenant (Mr. Henry) about the past military events (It's been a bad summer; We lost three cars; It has been bad; You couldn't believe how bad it's been) and expresses his predictions as to the future military events (Next year will be worse; they will attack now; They say they are to attack). We qualify such flashback of the past events and flashforward of the future events concerning the topic from the present-time perspective as temporal inhomogeneity. Present, past and future tense forms alongside with temporally coloured lexical units (summer, next year, now) serve as lingual means of temporal inhomogeneity.

Besides, this example illustrates the case of functional reorientation - the shift of asymmetrical status and role relations of the interlocutors caused by different military ranks (major - lieutenant) to partly symmetrical ones which is expressed by the speaker's initial utterance (Hello. How are you?) and the informal friendly atmosphere of the whole conversation. Moreover, in the course of the interaction as the juncture of the conversation turns, the introduction of a new topic marked by the speaker's utterance (Rinaldi wrote you. Where is Rinaldi?) takes place. All those transformations indicate the rearrangements within the context model in the course of communication, which inevitably lead to topic recontextualization in the discourse.

After deep and thorough analysis of factual material we have come to the conclusion that the communicative status of topic recontextualization includes the following communicative factors: spatio-temporal inhomogeneity; redistribution of communicative roles; side-participant presence; polytopicality of communication.

\section{Spatio-temporal inhomogeneity as a factor of topic recontextualization}

The spatio-temporal coordinates of communication that takes place in a given space and at a given time are marked by such deictic elements of the present as "here" and "now". However, in the course of an interaction there often appears the necessity of "virtual" transference in space and time to the plane of the past, or the future, and the reconstruction of the event that took place, or will take place. Such coexistence of 
different spatio-temporal planes within one communicative situation is qualified as spatio-temporal inhomogeneity. The change of the spatio-temporal reference of the topic marks its reperspectivation, and therefore its recontextualization.

Retrospection (flashback) presupposes the transference from the present time and space to the past. Prospection (flashforward) indicates the transference from the present time and space to the future. Retrospection and prospection are based on the psychological ability of interlocutors to keep and actualize in their memory the prior and the posterior topical information, and to correlate it with the current one.

One should consider the reference of the topic to the plane of the past, or the future, in terms of the retrospective and the prospective references due to which distant (remote in space and time) contextual models are actualized.

A retrospective reference of the topic consists in the fact that the speaker makes an "anchor" of the topic to past events. Retrospection restores in to the memory and recontextualizes the previous events and provides an opportunity to rethink the topic within a new contextual model.

Considering the results of a thorough analysis, we isolated the lexico-grammatical indicators, which serve as the lingual means of the retrospective reference. To the lexical indicators of past events we note temporal adverbs (yesterday, recently, lately, once, before, earlier, ago, etc.), temporal adjectives (past, last, former, previous, etc.) and temporal nominal groups (one day (night), some years ago, some time before, two years later, etc.). The grammatical indicators of the retrospective reference are represented by the past forms of the verbs and the subordinate clauses of time.

Analyze the following example:

(2) Dr. Wiley scrutinized Charles's anxious face. He saw that Charles had aged a lot since he was a student [...].

S1 "Michelle has leukemia, Charles", said Dr. Wiley.

Charles's mouth slowly dropped open. His blue eyes glazed as if he were in a trance. He didn't move a muscle; he didn't even breathe. It was as if Dr. Wiley's news had released a flood of banished memories [...].

S2 "Is this all some elaborate joke?", snapped Charles.

S1 "It's not a joke”, said Dr. Wiley. He spoke gently, but firmly. "Charles, I know this is difficult for you, especially because of what happened to Elizabeth some years ago. But you have to get control of yourself. Michelle needs you" (Cook, 1982: 75-76).

The example (2) shows that the topic of the dialogue between Dr. Wiley and Charles (father) is Michelle's fatal disease (Michelle has leukemia). In the course of communication Dr. Wiley recontextualizes the topic by the means of reminding Charles of the fact that some years ago his wife died from this disease (what happened to Elizabeth some years ago). The retrospective reference of the topic is realized by the past tense form of the verb (happened) and the temporal nominal group (some years ago). Besides, the flashback is accompanied by non-verbal movements (mouth slowly dropped open; eyes glazed as if he were in a trance; didn't move a muscle; didn't even breathe) and prosodic means (snapped, spoke gently, but firmly).

A prospective reference of the topic consists in the speaker's reproduction of the potentially relevant information concerning the topic in the temporal plane of the future. 
To the lexical indicators of future events we refer to the temporal adverbs (tomorrow, soon, etc.), temporal adjectives (next, coming, following, etc.), and temporal nominal groups (next week, in some days, etc.). The grammatical indicators of the prospective reference are represented by the future forms of the verbs and the subordinate clauses of time.

Consider the following example:

(3) Birkin laughed. Gerald looked at his face, as it lay there laughing and bitter and indifferent on the pillow, and he could not go away.

S1 "I don't suppose you will see very much more of Gudrun, at least. She is a restless bird, she'll be gone in a week or two", said Birkin.

S2 "Where will she go?"

S1 "London, Paris, Rome - heaven knows. I always expect her to sheer off to Damascus or San Francisco; she's a bird of paradise. God knows what she's got to do with Beldover. It goes by contraries, like dreams" (Lawrence, 1997: 131).

In the given conversation (3) the speaker (Birkin) informs his communicative partner (Gerald) about the future plans of their mutual friend (Gudrun) - "a restless bird of paradise" (She is a restless bird; she's a bird of paradise) - to visit many foreign countries. The lingual means of the prospective reference of the topic are expressed by the future tense forms of the verbs (will see; will be gone) and a temporal nominal group (in a week or two). London, Paris, Rome serve as lingual markers of the spatial reference of the topic.

As we see, spatio-temporal inhomogeneity as a factor of topic recontextualization finds its realization in retrospective and prospective references. Oppositely directed retrospective and prospective references of the topic also have some common characteristics. They both perform the function of the expansion of the cognitive potential of the context model and provide the topical multiperspectivity in the discourse.

\section{Redistribution of communicative roles as a factor of topic recontextualization}

The speaker and the listener change their communicative roles one by one in the course of an interaction. The speaker introduces the topic and contextualizes it by the means of giving it a definite reference based on the relevant context model. The listener identifies and evaluates the speaker's topic depending on his own context model.

Our scientific observations have proved the fact that the listener is not just a passive "consumer" of information, but an active participant who contributes a lot to the communicative success. In the course of an interaction there are cases in which the taking of the communicative initiative by the listener, causes a violation of the regular distribution of the interlocutors' roles called redistribution. By changing their places, the communicative partners undergo a so-called "mirror" transformation. Such a "rotation" certainly leads the qualitative reconstruction of the context model, i.e. recontextualization.

The profound factual material analysis enabled us to single out the cases of the redistribution of the interlocutors' roles: a) a free-will transference of the 
communicative initiative by the speaker to the listener and b) a self-willed seizure of the communicative initiative by the listener.

Free-will transference of the communicative initiative by the speaker to the listener is regarded as a "self-withdrawal" of the speaker from his dominating position in the topic contextualization. The speaker transfers the communicative initiative to the listener and, as a result, the topic undergoes certain modifications. Now it is the listener (potential speaker2) who contextualizes the topic based on his context model. Such expressions as "you know all about...", "you are an expert in ...", "it's better for you to know" and the like serve as the lingual markers of the free-will transference of the communicative initiative by the speaker to the listener.

Analyze the following example:

(4) He came back in a few moments and devoted himself to the ancient (and often, it seemed to me, timewasting) Irish ritual of steeping and pouring the tea. He did so with the grace of a bishop presiding over a solemn liturgy.

S1 "You are a desperate man altogether, Dermot Michael Coyne... Now what is it you want to know?"

S2 "You can tell me about Maamtrasna."

S1 "Ah", he said shifting uneasily. "Yet it is a grand story, one that ought to be told... Would you be after thinking about telling it yourself? You know a lot about it, Jack Lane. Aren't you the one who should be telling the story?"

S2 "I might, if you don't mind... You said it ought to be told..." (Greeley, 2002: 50-51).

In the example (4) the speaker transfers the communicative initiative to the listener because he considers the listener to be more knowledgeable about the suggested topic. The lingual markers of the redistribution of interlocutors' roles are represented by the expressions Would you be after thinking about telling it yourself? You know a lot about it; Aren't you the one who should be telling the story? The speaker2's final remarks (I might, if you don't mind and You said it ought to be told) serve as the lingual means of topic recontextualization.

Self-willed seizure of the communicative initiative by the listener is considered as a "self-nomination" of the listener for the role of the speaker. The listener changes his subordinating position of the topic interpreter to the dominating position of the author.

The communicative tactics of attracting attention, interruption and persuasion applied by the listener (potential speaker2) signal the redistribution of the communicative roles.

Tactics of attracting attention. The listener takes the communicative initiative in his hands and recontextualizes the topic. He gives the communicative process a new impulse and prevents the untimely finishing of communication. Such speech clichés like "I say...", "Look here...", "What about...?" "How about...?" serve as the lingual means of increasing the speaker's interest in the topic being discussed and encouraging his further active participation.

Consider the following example:

(5) S1 "I'm not in the least sorry. Of course, it's just a waste of money keeping me on at school. It was cruel to put me under the guardianship of people who know nothing about things". 
S2 "Is it true that you're very anxious to leave?"

S1 "Yes, sir".

S2 "Are you unhappy here?"

Philip blushed. He hated instinctively any attempt to get into the depths of his feelings.

S1 "Oh, I don't know, sir".

Mr. Perkins seemed to speak almost to himself. $\mathbf{S 2}$ "Of course, schools are made for the average. The holes are all round, and whatever shape the pegs are they must wedge in somehow. One hasn't time to bother about anything but the average". Then suddenly he addressed himself to Philip: "Look here, I've got a suggestion to make to you. It's getting on towards the end of the term now. Another term won't kill you, and if you want to go to Germany you'd better go after Easter than after Christmas. It'll be much pleasanter in the spring than in midwinter. If at the end of the next term you still want to go I'll make no objection" (Maugham, 1991: 138).

The example (5) illustrates that observing the topic "shading" (it's just waste of money keeping me on at school) and its negative verbal (waste of money, cruel) and non-verbal (blushed) evaluation by the speaker (Philip), the listener (Mr. Perkins) takes the communicative initiative in his hands and gives "new life" to the topic. A speech cliché (Look here) serves as a lingual means of topic recontextualization.

Tactics of interruption. The speaker recontextualizes the topic introduced by the speaker taking into account his own context model. Such expressions as "I'm sorry to interrupt you", "just a minute”, "excuse me for snapping up", "sorry for cutting off" and the like, serve as the lingual markers of the self-willed seizure of the communicative initiative by the listener.

Analyze the following example:

(6) Charles moved to the edge of his seat. For him the issue was crystal clear and he was astounded that he and Ibanez could view the event from such fundamentally different perspectives. Closing the door behind Brighton, Dr. Ibanez came back to his desk and sat down. His mood had abruptly switched to tired irritation. He eyed Charles across the expense of his desk.

S1 "Dr. Ibanez", began Charles, "I..."

S2 “Just a minute, Charles”, interrupted Ibanez, his eyes boring into Charles's face.

S1 "Dr. Ibanez", Charles broke in. "I really want to say something".

S2 "In a minute, Charles. Can you tell me your latest publications?" (Cook, 1982: 51).

In the example (6) the listener (Dr. Ibanez) makes an attempt to seize the communicative initiative and recontextualizes the topic based on his context model. The utterances, Just a minute; In a minute; Can you tell me your latest publication? serve as the lingual markers of topic recontextualization and the verb interrupts signals about the redistribution of the interlocutors' roles.

Tactics of persuasion. Taking others' perspective is a vivid example of reperspectivation and thus recontextualization, especially in the communicative acts of persuasion which serve as an attempt to bring divergent perspectives to convergence.

C.F. Graumann states, "besides expressing myself and appealing to my partner's attention I refer my partner not only to an object or state of affairs but I also try to make him or her see (understand, conceive, judge, etc.) it the way I do, i.e. from my point of view. Whatever I present as my view on a given matter, I offer as a potential perspective for others. The capacity to take the other persons' perspectives 
may be considered the elementary communicative competence" (Graumann \&Werner, 2002: 15).

Consider the following example:

(7) S1 "I've got a better idea", said Charles. "Why don't I go over Morrison's head to the director and just lay the cards on the table, explain that it's infinitely more important for us to stay with our own work".

S2 "I can't imagine it will help", cautioned Ellen. "Morrison told you the decision came from the board of directors... I think you are just asking for trouble".

S1 "And I think it's worth the risk".

S2 "Well, you're right" (Cook, 1982: 47).

The example (7) clearly shows that Charles is convinced that the open talk with the director may change his difficult position for the better and is making an attempt to persuade Ellen that it's worth doing (I've got a better idea; I think it's worth the risk). At first Ellen doubts the appropriateness of his actions (I can't imagine it will help; I think you are just asking for trouble), but at last she changes her perspective on the topic and her final utterance (Well, you're right) signals the convergence of interlocutors' perspectives.

Effective communication presupposes "the accommodation of conversationoriented and dialogue-oriented viewpoints" and thus the integration of functional values anchored to minimally two co-participants, topic and discourse (Fetzer, 2004: 79]. It is a generally accepted rule that a person who is less knowledgeable about the topic will take his partner's perspective. Participants may argue about different aspects of the topic under discussion, but sooner or later their divergent perspectives sufficiently converge providing effective interaction. The only exception is the case when one of the interlocutors is absolutely ignorant about the topic. In such a case the dialogical movement is unidirectional (from the informed to the uninformed participant and not vice versa).

\section{Side-participant presence as a factor of topic recontextualization}

The canonical structure of any communicative situation has two communicative partners (the speaker and the listener). However, our thorough analysis of the factual material has proved the fact that there are numerous communicative situations with an extended anthropological structure. It means that apart from the obligatory participants, they are marked by the presence of a third participant - a side-recipient.

Language interaction corresponds to the communicative activity as a symbiosis of the speech actions of the speaker, the listener and the observer (Vasiliev, 1985: 28-29) and thus confirms the existence of the third participant - the side-recipient as a relevant subject of communication.

As N. Vorontsova states (Vorontsova, 2009), the side-recipient is the anthropological component of the verbal interaction who doesn't belong to the active participants, but is located within the zone of audio-perception of the verbal contact between the interlocutors, and thus is able to receive the producent's (the speaker's) utterance directed towards the listener and to perform the role of the interpreter of the content of this utterance. 
According to G. Brown (Brown, 1995), when the third person appears, one more context is added. When the speaker's and the listener's context models are in the episodic memory of the side-participant, a mental representation of the communicative situation, i.e. the side-participant's context model is generated. As a result, the presence of the sideparticipant provokes some changes in the context model structure. The complementarity and integration of all the participants' context models lead to the construction of the integrated context model with an expanded structure.

The side-recipient can perform the role of either a passive, or an active participant of communication. As a passive participant, the side-recipient simply observes the communicative process between the speaker and the listener, and contextualizes the suggested topic "silently" depending on his own context model.

The communicative function of the side-recipient as a passive participant, i.e. the observer of the communicative process, is expressed in his ability to regulate the communicative activity of the interlocutors, (the speaker and the listener). This is manifested in the verbal (interruption of the talk, or topic change), and non-verbal (whispering instead of speaking aloud, distancing in space to avoid eavesdropping) self-restraints of the communicative partners.

Analyze the following example:

(8) S1 "She should go on a diet".

S2 "But as long as you are tinier than she is, she can disdain you for that as well as for your success, can't she?"

S1 "You noticed".

S2 "Does she have to treat me like I'm some egomaniacal fan seeker? It's part of my business - an important part - and there are times when I hate it [...]. She should know that".

S1 "Deep down inside, I'm sure she does".

S2 "You know something? She's never said one nice thing about what I do. It's like I don't even do it [...]. Would it hurt her, for God's sake?"

S1 “Judy's not a happy woman, Tess. Shh, here she comes" (Spencer, 1998: 57-58).

In the example (8) the appearance of the side-recipient marked by the utterance (here she comes) and the phonation signal (Shh) cause the interruption and the untimely finishing of the talk between the speaker and the listener in which the topic of communication is the personality of the side-recipient (Judy).

In the communicative situations that take place in the side-recipient's presence the so-called "paradox of the observer" comes into action, i.e. the speaker and the listener are reluctant to be heard and overheard by the side-recipient, especially when the topic under discussion is a confidential one.

However, there are cases when the side-recipient becomes an active participant of the interaction and "verbalizes" his own perspective on the topic. The dynamics of the side-recipient's communicative position is expressed in the functional transformation of his communicative status: from the passive observer to the active participant (speaker 3).

The side-recipient's active position is realized in his verbal reaction on the topic under discussion and consists in his adequate perceiving and interpreting the information obtained as a result of observing the process of topic contextualization by the speaker and the listener. The lingual means of the modification of the side- 
recipient's communicative status are expressed by the following verbs: to say, to tell, to ask, to explain, to interfere, to intrude, to break in, to butt in and so on.

Consider the following example:

(9) $\boldsymbol{S 1}$ "You to understand it Mr. Ablewhite, if you please".

S2 "I'm also to take it as a matter of fact that the proposal to withdraw from the engagement came, in the first instance, from YOU?"

$\mathbf{S 1}$ "It came, in the first instance, from me. And it met, as I've told you, with your son's concern and approval" [...].

S2 "My son is a mean-spirited hound! cried this furious old wordling".

S1 "In justice to myself as his father - not in justice to HIM - I beg to ask you, Miss Verinder, what complaint you have to make of Mr. Godfrey Ablewhite?"

S3 (side-recipient) Here Mr. Bruff interfered. "You are not bound to answer this question", he said to Rachel, touching her arm.

S1 "Don't forget, sir", he said, "that you are a self-invited guest here" (Collins, 2002: 54).

The example (9) illustrates that the side-recipient (Mr. Bruff) makes an attempt to intrude into the quarrel between Mr. Godfrey Ablewhite and Rachel. In such a way he recontextualizes the topic under discussion (You are not bound to answer this question) taking into consideration his own context model. The verb interfere serves as a marker of the communicative activity of the side-recipient. But such self-willed intrusion of the siderecipient into the communicative process causes the speaker's negative reaction (Don't forget, sir, that you are a self-invited guest here).

\section{Polytopicality of communication as a factor of topic recontextualization}

Generally speaking, the topic is a relatively permanent (fixed) thematic object of the communicative interaction between the speaker and the listener.

Analyze the following example:

(10) Skillful, male hands caressed her [Claire] and lean hips moved in slow, sensuous circles against her thighs. She arched in restless frustration, seeking relief for the sweat, aching need building inside her.

S1 "Spend the rest of your stay in Sydney with me", Brett's voice urged her.

It was what she had longed to hear. A feverish desire to agree overwhelmed her.

S2 "Yes... Oh, yes! I've got to go away on business for a couple of days, but when I get back we'll spend the rest of the time together" (Hadley, 1993: 80).

The existence of the only one permanent topic (Spend the rest of your stay in Sydney with me) characterizes the communication given above as monotopical. It should be taken into account that monotopicality presupposes the thematical "smoothness" of the communicative process. It means that the speaker (Brett) realizes the communicative initiative by means of her speech turn and defines the topical field for the realization of her interlocutor's speech turn (Claire). The communicative actions of the speaker and the listener complement each other revealing different aspects of the topic under discussion. Topic recontextualization caused by the temporal inhomogeneity finds its realization in the prospective reference - reproduction of the potentially relevant information 
concerning the topic in the temporal plane of the future (I've got to go away on business for a couple of days, but when I get back we'll spend the rest of the time together). The temporal inhomogeneity is expressed by the future tense form of the verb (we'll spend), the subordinate clause of time (when I get back) and the temporal nominal group (for a couple of days).

However, our scientific research has proved that there are numerous cases when two or more topics coexist and find their realization in cause of interaction. It signals topic fluctuation (flexibility) and characterizes the communication as polytopical. The global topic is rather "free" while local topics appear one by one. The interlocutors' speech turns being incoherent with each other at the moment of the introduction of a new topic generate the potential polytopical field of communication.

The intense debates evolve in dynamic, partly unpredictable ways, much like multi-party conversations in which topics emerge, disappear or branch off into quite different topics, stay on and get transformed as the contexts change, and as a consequence, new perspectives on partly the same and partly new subject matters appear. These reperspectivation processes thus recontextualize the discursive treatment of particular events into debates that are of a long-lasting nature (Graumann, Werner, 2002: 52).

Consider the following example:

(11) S1 "I hear you killed people for the wise guys out on the coast".

$\mathbf{S 2}$ "You are talking to the wrong man, my friend..."

$\mathrm{S1}$ "Let me raise another subject. I understand you've made some remarks about my wife".

S2 "I don't know where you heard that, but it's not true. I have the greatest respect to your wife", he said. I said.

S1 "Maybe we can take up the subject another time. On a more physical level",

S2 “I've got to run. Get a good night's sleep..." (Burke, 2000: 156).

In the example (11) the interlocutors discuss the topic of killing, introduced by speaker1, which turns to be unpleasant for speaker2. Unexpectedly they switch to another topic (remarks about a wife) partly modifying their context models. As we see, topic changing takes place rather suddenly and incoherently being unprepared by the previous speech turn of the discourse unlike the so-called "evolutionary development" of the global topic in the coherent succession of the local topics. In this case the strategy of topic change is used as manipulative in order to avoid a potential conflict. The utterance, "Let me raise another subject.", serves as a lingual marker of topic recontextualization, and the emergence of different perspectives of the interlocutors on the new topic.

There are cases when the side-recipient as a result of changing his communicative role from the passive observer to the active participant displays the desire to introduce his own topic for discussion rather spontaneously.

As a rule, the process of recontextualization of the new topic by the siderecipient is explicated in the discourse by the tactic of "taking the floor". Such a tactic is realized by "phatic" speech turns like, "Excuse me, may I ask you?" "Sorry for interrupting you, but ..." and so on.

Analyze the following example: 
(12) The studio was large and bare, with gray walls, on which were pinned the studies that had received prizes. A model was sitting in a chair with a loose wrap thrown over her.

S1 "Oh, there's nothing like that here", she [Mrs. Otter] said. "You see, about half our students are ladies, and they set a tone to the place". Then she turned to the model. "La Pose".

S2 "It's a stupid pose", said Miss Price. "I can't imagine why they chose it".

When Philip entered, the people in the studio had looked at him curiously, and the model gave him an indifferent glance, but now they ceased to pay attention to him. Philip, with his beautiful sheet of paper in front of him, stared awkwardly at the model. He did not know how to begin. He glanced at Miss Price's work.

S3 (side-recipient) "Sorry for interrupting you, but I should have thought I could do as well as that", he said (Maugham, 1991: 286-287).

The example (12) clearly shows that during the process of communication the side-recipient (Philip) changes his communicative status: from the passive observer expressed by non-verbal means (entered, with his beautiful sheet of paper in front of him; stared awkwardly at the model) to the active participant introducing a new topic (I should have thought I could do as well as that) in the discourse that is intensified non-verbally (glanced at Miss Price's work). For topic recontextualization he involves the tactic of "taking the floor" (Sorry for interrupting you, but...).

\section{Conclusion}

Considering the results of our research, we may conclude that understanding context as a mentally construed subjective representation of the relevant parameters of a communicative situation in episodic memory of its participants gives the opportunity to differentiate the speaker's and the listener's context models which overlap in the process of communication.

Topic as an object of the speaker's thought can be appropriately identified by the listener under condition of activating the relevant context model. Topic contextualization is marked by the perspective impact - a speaking stance or position according to which a topic is viewed and interpreted. Perspective change or reperspectivation results in context model modification and consequently in topic recontextualization.

Topic recontextualization is a discourse-based phenomenon aimed at the functional topic reorientation caused by the change of the interlocutors' perspective on a topic. Spatiotemporal inhomogeneity, redistribution of communicative roles, side-participant presence and polytopicality of communication expressed by various lingual means form the communicative status of topic recontextualization in the discourse.

The given study opens up new prospects for further research of gender and ethnocultural peculiarities of topic recontextualization in the discourse. 


\section{References}

Brown, Gillian. 1995. Speakers, Listeners and Communication: Explorations in Discourse Analysis. Cambridge: Cambridge University Press.

Dijk, Teun A. van. 2008. Discourse and Context: A Sociocognitive Approach. New York: Cambridge University Press.

Duranti, Alessandro, Goodwin, Charles. 1995. Rethinking Context. Cambridge: Cambridge University Press.

Fetzer, Anita. 2004. Recontextualizing Context: Grammaticality Meets Appropriateness. Amsterdam/Philadelphia: John Benjamins Publishing Company.

Graumann, Carl F., Kallmeyer, Werner. 2002. Perspective and Perspectivation in Discourse. Amsterdam / Philadelphia: John Benjamins Publishing Company.

Gumperz, John J. 1982. Discourse Strategies: Studies in Interactional Sociolinguistics. Cambridge: Cambridge University Press.

Linell, Per. 1998. Approaching Dialogue: Talk Interaction and Contexts in Dialogical Perspectives. Amsterdam / Philadelphia: John Benjamins Publishing Company.

Pilkington, Adrian. 1996. "Introduction: Relevance Theory and Literary Style". Journal of Language and Literature 5 (3): 157-162. https://doi.org/10.1177/096394709600500301.

Simpson, Paul. 1993. Language, Ideology and Point of View. London, New York: Routledge.

Vasiliev, Leonid. 1985. Nekotoryie Aspekty Yazykovoi Deyatelnosti. Pragmaticheskie i semanticheskie aspekty sintaksisa: 28-35. Kalinin: Kalininsk. gos. un-t.

Vorontsona, Natalia. 2009. Komunikatyvna interaktsiia zi storonnim retsypiientom: lingvopragmatychnyi i kognityvnyi aspekty. Kremenets.

Burke, James L. 2000. Purple Cane Road. New York: Dell Publishing.

Collins, Wilkie. 2002. The Moonstone. Kindle edition.

Cook, Robin. 1982. Fever. New York: New American Library.

Greeley, Andrew.M. 2002. Irish Love. New York: Tom Doherty Associates.

Hadley, Liza. 1993. Not Such a Stranger. Richmond: Eton House, Mills and Boon Ltd.

Hemingway, Ernest. 2003. A Farewell to Arms. London: Penguin books.

Lawrence, David. H. 1997. Women in Love. Wordsworth Editions Ltd.

Maugham, Somerset W. 1991. Of Human Bondage. New York: Bantam Classics.

Spencer, LaVyrle. 1998. Small Town Girl. New York: Jove Books. 